\title{
Seasonality in the Incidence of Breast Cancer in Teenage and Young Adult Females in Northern England, 1968-2005
}

\author{
Nermine O. Basta ${ }^{1}$, Peter W. James ${ }^{1}$, Alan W. Craft ${ }^{2}$ and Richard J.Q. McNally ${ }^{*}, 1$ \\ ${ }^{I}$ Institute of Health and Society, Newcastle University, Sir James Spence Institute, Royal Victoria Infirmary, Newcastle \\ upon Tyne NE1 4LP, England, UK \\ ${ }^{2}$ Northern Institute of Cancer Research, Newcastle University, Sir James Spence Institute, Royal Victoria Infirmary, \\ Newcastle upon Tyne NE1 4LP, England, UK
}

\begin{abstract}
There are few studies that focus on risk factors for breast cancer in teenagers and young adults. Known risk factors for breast cancer in females include family history of breast cancer and environmental exposure to carcinogens. Seasonal variation suggests that environmental factors may be involved in aetiology. The aim of this study was to investigate seasonal variation in breast cancer incidence among 15-24 year old females. Details of 42 cases, diagnosed during 1968-2005, were extracted from a specialist registry. Seasonal variation was analysed with respect to months of birth and diagnosis using the chi-squared heterogeneity test to examine non-uniform variation. Poisson regression analysis was used to fit sinusoidal models. There was significant heterogeneity for breast carcinoma $(P=0.045)$, based on month of birth showing evidence of a seasonal effect. This finding of seasonal variation around time of birth amongst females with breast carcinoma is highly novel and suggests a possible early aetiological involvement of environmental factors.
\end{abstract}

Keywords: Epidemiology, aetiology seasonality, breast cancer, teenage and young adult, England.

\section{INTRODUCTION}

Breast cancer in adolescent and young adult women is rare, but when it occurs it tends to be more aggressive and has a worse prognosis than in older women [1]. There are few studies that focus on risk factors for breast cancer in teenagers and young adults. Known risk factors for breast cancer in females of all ages include older age, reproductive factors (such as early menarche, nulliparity, older age at first full term birth and greater number of full term pregnancies), family history of breast cancer and environmental exposure to carcinogens [2, 3]. Environmental exposures may cause germ cell mutations. Pathological mutations in breast cancer susceptibility genes, BRCA1 and BRCA2, were found to be associated with an increased risk of breast cancer [4].

In the United Kingdom (UK) there are four seasons: winter $\left(21^{\text {st }}\right.$ December - $20^{\text {th }}$ March), spring (21 ${ }^{\text {st }}$ March $20^{\text {th }}$ June $)$, summer $\left(21^{\text {st }}\right.$ June $-20^{\text {th }}$ September $)$ and autumn $\left(21^{\text {st }}\right.$ September $-20^{\text {th }}$ December $)$. The average maximum temperatures in winter range from $6^{\circ} \mathrm{C}$ to $10^{\circ} \mathrm{C}$, in spring from $13^{\circ} \mathrm{C}$ to $20^{\circ} \mathrm{C}$, in summer from $19^{\circ} \mathrm{C}$ to $22^{\circ} \mathrm{C}$ and in autumn from $7^{\circ} \mathrm{C}$ to $14^{\circ} \mathrm{C}$. Seasonal variation in the month of birth would suggest that exposures acting close to birth are relevant to aetiology. On the other hand, seasonal variation in the month of diagnosis would suggest the involvement of seasonally varying environmental factors close to time of diagnosis.

\footnotetext{
*Address correspondence to this author at the Institute of Health and Society, Newcastle University, Sir James Spence Institute, Royal Victoria Infirmary, Queen Victoria Road, Newcastle upon Tyne NE1 4LP, England, UK; Tel: +44(0)-191-2821356; Fax: +44(0)-191-2824724; E-mail: Richard.McNally@ncl.ac.uk
}

The aim of this study was to examine seasonality in the incidence of breast carcinoma by month of birth and, separately, month of diagnosis amongst 15-24 year old females, diagnosed during the period 1968-2005, in a geographically defined area of northern England, UK.

\section{METHODS}

\section{Study Subjects}

All cases of female breast carcinoma, aged 15-24 years, and diagnosed during the period 1968-2005 were obtained from the Northern Region Young Persons' Malignant Disease Registry (NRYPMDR). The NRYPMDR is a specialist population-based cancer registry covering a defined geographical area of northern England (counties of Northumberland, Tyne and Wear, Durham, Teesside, and Cumbria, excluding Barrow-in-Furness). All cases of cancer in the region, diagnosed in 0-24 year olds, are notified to the registry. Patients are identified from multiple sources. Consultants throughout the region notify the registry of any malignancies in children and young adults. Death certificates and hospital admissions are regularly checked. Data are periodically cross-checked with regional and national cancer registries. The NRYPMDR has a high level of overall completeness and ascertainment, estimated to be more than 98\% [5]. The International Classification of Diseases for Oncology, third edition (ICDO-3) was used for coding morphology and primary site of diagnosis [6]. The NRYPMDR is exempted (originally under Section 60 of the UK Health and Social Care Act 2001, which has now been superseded by Section 251 of the UK National Health Service Act 2006) from the need to obtain patient consent for recording and analysis of data. 
Table 1: Number of Breast Cancer Patients by Month of Birth and Month of Diagnosis

\begin{tabular}{|c|c|c|c|c|c|c|}
\hline \multirow{3}{*}{ Month } & \multicolumn{6}{|c|}{ Breast cancer patients } \\
\hline & \multicolumn{3}{|c|}{ Birth } & \multicolumn{3}{|c|}{ Diagnosis } \\
\hline & Observed counts & Expected counts* & $\mathbf{O} / \mathbf{E}^{\S}$ ratio & Observed counts & Expected counts** & $\mathbf{O} / \mathbf{E}^{\S}$ ratio \\
\hline January & 5 & 3.87 & 1.29 & 2 & 3.42 & 0.59 \\
\hline February & 2 & 3.53 & 0.57 & 3 & 2.92 & 1.03 \\
\hline March & 1 & 3.70 & 0.27 & 3 & 3.89 & 0.77 \\
\hline April & 8 & 3.73 & 2.14 & 3 & 3.87 & 0.77 \\
\hline May & 2 & 3.72 & 0.54 & 4 & 3.56 & 1.12 \\
\hline June & 6 & 3.09 & 1.94 & 4 & 3.83 & 1.04 \\
\hline July & 5 & 3.53 & 1.42 & 3 & 3.74 & 0.80 \\
\hline August & 0 & 3.50 & 0.00 & 3 & 2.89 & 1.04 \\
\hline September & 3 & 3.60 & 0.83 & 4 & 2.85 & 1.40 \\
\hline October & 2 & 3.82 & 0.52 & 3 & 3.52 & 0.85 \\
\hline November & 6 & 2.93 & 2.05 & 4 & 4.07 & 0.98 \\
\hline December & 2 & 2.98 & 0.67 & 6 & 3.45 & 1.74 \\
\hline Total & 42 & 42 & 1 & 42 & 42 & 1 \\
\hline
\end{tabular}

* adjusted using the distribution of births of all cancer patients registered by the Northern Region Young Persons' Malignant Disease Registry ** adjusted using the distribution of diagnoses of all cancer patients registered by the Northern Region Young Persons’ Malignant Disease Registry ${ }^{\S}$ Observed/Expected

\section{Statistical Analysis}

The analysis was performed in the following stages. First, the overall distributions of births and diagnoses, from the NRYPMDR, were used as "proxies" for the underlying distributions of births and cancer diagnoses in the study region. All cases of malignancies recorded by the NRYPMDR from 1968 - 2005 were used to examine overall monthly variation in the distribution of birth months and diagnosis months for all cancers together. This determined if there was evidence of overall seasonal patterns in the total data set. If such seasonality is present then the expected numbers of births and diagnoses for breast carcinoma patients would require corrective adjustments. Secondly, a chi-squared test for heterogeneity was used to test for a seasonal effect in the adjusted breast cancer data. The test shows the presence of any departure from a uniform distribution throughout the year. Thirdly, Poisson regression models were used to determine the pattern of seasonality for cases of breast cancer. These models were used to fit sinusoidal (harmonic) models to the data, using month of birth and, separately, month of diagnosis as a covariate. The time at which the maximum incidence occurred was estimated using a single annual peak within the period of a year. The significance of the sinusoidal model assumption was evaluated by using a chi-square goodness of fit test. Analyses were also performed by two sub-periods of diagnosis (1968-1986; 1987-2005). As the numbers of cases observed per period were small, simulation was carried out to test the validity of the results. Statistical significance was taken to be $P<0.05$. All statistical analyses were performed using Stata version 10.

\section{RESULTS}

There was evidence of statistically significant heterogeneity in the overall distribution of all cancer cases for month of birth $(P=0.02)$ and month of diagnosis $(P=$ $0.0002)$. Therefore, overall case distributions were then used to correct the case distributions of birth dates and diagnostic dates for cases of breast carcinoma. There were 42 patients with breast carcinoma diagnosed in adolescent and young adult females during the study period. Table 1 shows the observed and expected numbers of patients born and diagnosed in each month. There was significant heterogeneity in month of birth for breast carcinoma patients $(P=0.045)$ (Table 2, Fig. 1), showing evidence of a seasonal effect around the time of birth, with more cases observed in the spring (April - June) and late autumn / early winter (November - January) months. However, this seasonal variation did not follow a sinusoidal pattern $(P=0.79)$. Additional analysis by sub-period of diagnosis showed this effect for patients diagnosed before $1987\left(n=23, \chi^{2}=21.67\right.$, $P=0.027)$ but not for patients who were born in the later period of the study $\left(n=19, \chi^{2}=14.80, P=0.19\right)$. Simulated results based on 1000 independent random samples showed for a sample size of $n=23$, with goodness of fit statistic 21.34 , there was evidence of heterogeneity (exceeding the $95 \%$ simulation based critical value of 19.3). There was no evidence of seasonal variation based on month of diagnosis $(P=0.98)$.

Table 2. Results of Statistical Tests of Seasonal Variation for Breast Cancer in Teenage and Young Adult Females

\begin{tabular}{|l|c|c|c|}
\hline \multirow{2}{*}{} & \multicolumn{3}{|c|}{ Breast Cancer Patients } \\
\cline { 2 - 4 } & $\mathbf{N}$ & $\begin{array}{c}\text { Heterogeneity } \\
\boldsymbol{P} \text {-value }\end{array}$ & $\begin{array}{c}\text { Sinusoidal } \\
\boldsymbol{P} \text {-value }\end{array}$ \\
\hline \hline Month of birth & 42 & $0.045^{*}$ & 0.79 \\
\hline Month of diagnosis & 42 & 0.98 & 0.82 \\
\hline
\end{tabular}

*Statistically significant result $P<0.05$ 


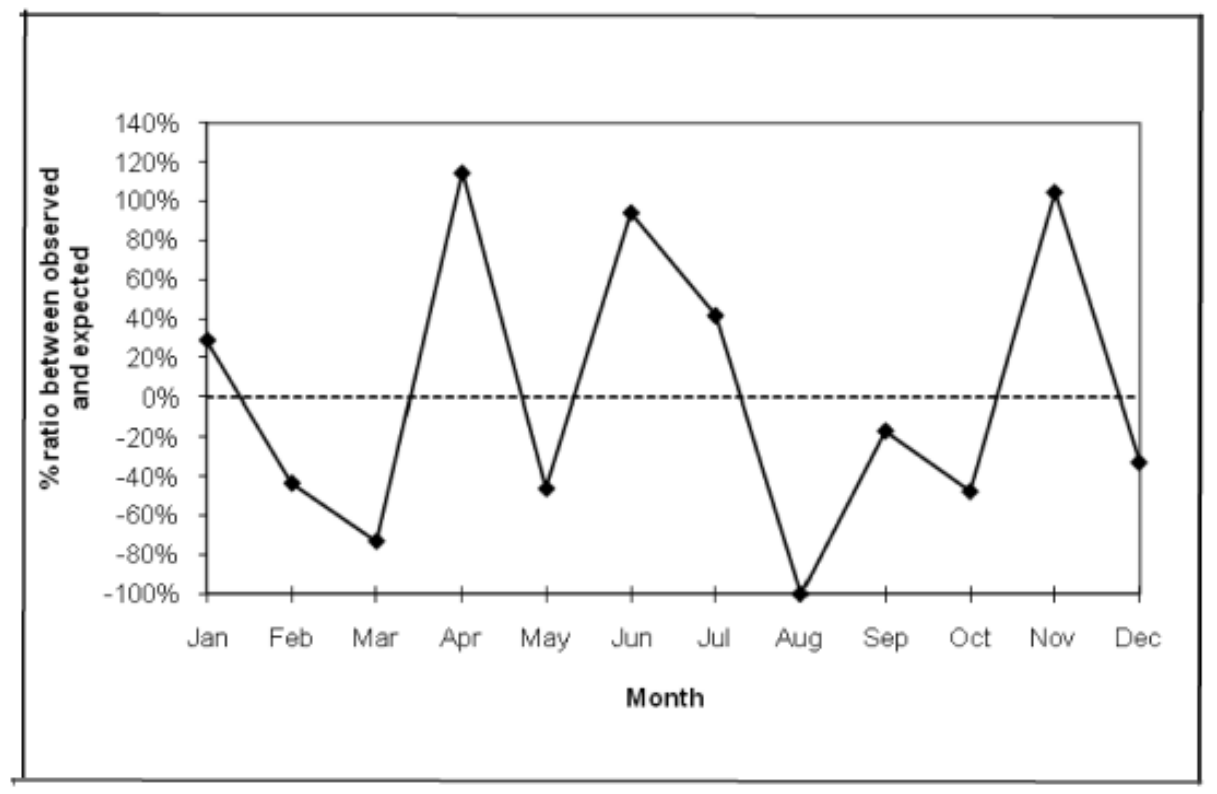

Fig. (1). Heterogeneity plot for breast carcinoma by month of birth.

\section{DISCUSSION}

In the present study we analysed seasonality in the incidence of breast carcinoma by month of birth and month of diagnosis in teenage and young adult (TYA) females who were resident in a geographically defined area of northern England. We found evidence of seasonal variation in month of birth for female breast carcinoma, in particular for those who were born before 1987. However, this variation did not follow a cyclical pattern. Based on month of diagnosis, there was no evidence of seasonal variation in the incidence of breast cancer in TYA. These results suggest that seasonal exposures close to the time of birth may be relevant risk factors for breast cancer in TYA, and that they were prevalent in the earlier years of the study.

Previous studies have explored the relationship between month of birth and breast cancer in women, but with inconsistent results [7-11]. Similar results to our findings were reported by one study of breast cancer in Greek women; they found two peaks in March and April in the spring and September in the autumn [7]. A study from Japan reported significant seasonal variation for premenopausal patients with a peak of births in the summer which was different from postmenopausal women who showed two peaks of births in the spring and the autumn [8]. However, in another large study from Japan, seasonal variations in month of birth were not statistically significant in any age group [9]. A large study from the USA found similar spring and autumn peaks in the month of birth for breast cancer patients; however they found the same distribution was also followed by other cancer cases [10]. A Swedish study reported a significant seasonal pattern for women born between 1880 and 1920 where those born in June had 5\% higher risk of breast cancer than those born in December [11]. It has been hypothesised that the intrauterine environment and, in particular, the in utero exposure to high levels of oestrogens is relevant to the aetiology of breast cancer in daughters [12]. Other epidemiological studies suggest that prenatal or early post-natal exposures may increase future breast cancer risk especially in young women $[13,14]$. Perinatal factors that have been studied and that may have a seasonal pattern are infections and maternal diet [13]. Factors such as maternal diet and environmental exposures may increase the risk of breast cancer by inducing permanent epigenetic changes in the foetus that alter the susceptibility to the other factors that can initiate breast cancer later in life [15]. In a large study, pathological mutations in breast cancer susceptibility genes were found in $20 \%$ of women with breast cancer diagnosed under the age of 30 years [4].

An inherent limitation of the study is that it is based on small numbers of cases from one geographical area, and may have arisen by chance. Potential confounding by cohort effects has been eliminated by conducting sub-period analyses. It was not possible to allow for confounding due to social deprivation in this analysis. However, the results from our study are consistent with the early involvement of environmental factors in the aetiology of breast cancer especially for patients diagnosed in the earlier period of the study, before 1987. Putative agents include maternal diet and perinatal infections [13].

\section{CONCLUSION}

This finding of seasonal variation around time of birth amongst females with breast carcinoma is highly novel and suggests a possible early aetiological involvement of environmental factors. Future studies are needed to examine larger data sets from a wider geographical area from the UK and other countries. Also, more extensive analyses should include women aged over 25 years. Further research work is needed to investigate hypotheses relating to specific infectious agents.

\section{CONFLICT OF INTEREST}

\section{None}




\section{ACKNOWLEDGEMENTS}

We thank the North of England Children's Cancer Research Fund for providing financial support. The Northern Region Young Persons' Malignant Disease Registry is funded by the Newcastle Hospitals NHS Trust.

\section{REFERENCES}

[1] Gajdos C, Tartter PI, Bleiweiss IJ, Bodian C, Brower ST. Stage 0 to stage III breast cancer in young women. J Am Coll Surg 2000; 190: 523-9.

[2] Woods WC, Hyman B, Muss HB, Solin LJ, Olopade OI. Malignant tumors of the breast. In: Cancer: Principles \& Practice of Oncology, $7^{\text {th }}$ ed. Edited by DeVita VT Jr, Hellman S, Rosenberg SA: Philadelphia, Pennsylvania: Lippincott Williams \& Wilkins; 2005: p. 1415

[3] Ewertz M, Duffy SW, Adami HO, et al. Age at first birth, parity and risk of breast cancer: a meta-analysis of 8 studies from the Nordic countries. Int J Cancer 1990; 46: 597-603.

[4] Lalloo F, Varley J, Ellis D, et al. Prediction of pathogenic mutations in patients with early-onset breast cancer by family history. Lancet 2003; 361: 1101-2.

[5] Cotterill SJ, Parker L, Malcolm AJ, Reid M, More L, Craft AW. Incidence and survival for cancer in children and young adults in the North of England, 1968-1995: a report from the Northern Region Young Persons' Malignant Disease Registry. Br J Cancer 2000; 83: 397-403.
[6] Fritz A, Percy C, Jack A, et al. (Eds). International Classification of Diseases for Oncology $(I C D-O)$. $3^{\text {rd }}$ ed. Geneva, Switzerland: World Health Organisation; 2000.

[7] Vassilaros S, Tsiliakos S, Adamopoulos D, et al. Seasona variations in the frequency distribution of breast cancer in Greek women according to the month of their birth. J Cancer Res Clin Oncol 1985; 110: 79-81.

[8] Nakao H. Birth seasonality of breast cancer patients and its variation according to menopausal status and histologic type in Japan. Eur J Cancer Clin Oncol 1986; 22: 1105-10.

[9] Hu YH, Kuroishi T, Matsushita Y, Nagata C, Shimizu H. Birth season and breast cancer risk in Japan. Breast Cancer Res Treat 1996; 39: 315-9.

[10] Severson RK, Davis S. Breast cancer incidence and month of birth evidence against an etiologic association. Eur J Cancer Clin Oncol 1987; 23: 1067-70

[11] Yuen J, Ekbom A, Trichopoulos D, Hsieh CC, Adami HO. Season of birth and breast cancer risk in Sweden. Br J Cancer 1994; 70: 564-8.

[12] Lagiou P. Intrauterine exposures, pregnancy estrogens and breast cancer risk: where do we currently stand? Breast Cancer Res 2006; 8: 112 .

[13] Innes $\mathrm{K}$, Byers $\mathrm{T}$, Schymura $\mathrm{M}$. Birth characteristics and subsequent risk for breast cancer in very young women. Am J Epidemiol 2000; 152: 1121-8.

[14] Xue F, Michels KB. Intrauterine factors and risk of breast cancer: a systematic review and meta-analysis of current evidence. Lancet Oncol 2007; 8: 1088-100.

[15] Hilakivi-Clarke L, de Assis S. Fetal origins of breast cancer. Trends Endocrinol Metab 2006; 17: 340-8. 